\title{
Parentalidade Adotiva: Contextualizando a Escolha
}

\author{
Rebeca Nonato Machado \\ Terezinha Féres-Carneiro \\ Andrea Seixas Magalhães \\ Pontifícia Universidade Católica do Rio de Janeiro \\ Rio de Janeiro, RJ, Brasil
}

\begin{abstract}
RESUMO
O presente estudo é parte de uma investigação mais ampla sobre a vivência de pais em relação à parentalidade e à filiação no período da adolescência de seus filhos adotivos. Procuramos analisar quais questões emocionais intersubjetivas, pertencentes ao início da formação dos vínculos afetivos, se atualizariam nesse período do ciclo familiar adotivo. Especificamente, neste trabalho, objetivamos explorar questões referentes às motivações para a escolha da parentalidade por adoção e o lugar da rede familiar como apoio na tomada de decisão. Realizamos um estudo de campo, baseado em entrevistas semiestruturadas com 10 sujeitos independentes, de classes média e alta da população do Estado do Rio de Janeiro. Verificamos que há uma hierarquia de preferência no processo de ter um filho, ficando a adoção como uma escolha secundária, e que a família extensa não tem interferência direta na tomada de decisão pela adoção.
\end{abstract}

Palavras-chave: Parentalidade; adoção; família; motivações; rede familiar.

\section{ABSTRACT}

\section{Adoptive Parenting: Contextualizing the Choice}

The present study is part of a wider investigation on the experience of parents related to parenting and the filiation in the adolescence of their stepchildren. It was analyzed which intersubjective emotional issues, belonging to the early formation of the affective ties would be updated during this time of the foster family cycle. Specifically, this study aimed to explore issues concerning the motivations for choice of parenting by adoption and the place of the family network to support the decision-making. There was a field study, based on semi-structured interviews with 10 independent subjects of middle and upper classes of the population in the state of Rio de Janeiro. It was found that there is a hierarchy of preference in the process of having a child, making the adoption a secondary choice, and the extended family has no direct interference in the decision-making by adoption.

Keywords: Parenting; adoption; family; motivations; family network.

\section{RESUMEN}

\section{Parentalidad Adoptiva: Contextualizando la Opción}

El presente estudio es parte de una investigación más amplia sobre la vivencia de padres en relación a la parentalidad y a la filiación en el período de la adolescencia de sus hijos adoptivos. Buscamos analizar cuales cuestiones emocionales intersubjetivas, pertenecientes al inicio de la formación de los vínculos afectivos, se actualizarían en ese período del ciclo familiar adoptivo. Específicamente, en este trabajo, tuvimos como objetivo explorar cuestiones referentes a las motivaciones para la opción de la parentalidad y el lugar de la red familiar como apoyo en la toma de decisión. Realizamos un estudio de campo, basado en entrevistas semi-estructuradas con 10 sujetos independientes, de clases media y alta de la población del Estado de Rio de Janeiro. Verificamos que hay una jerarquía de preferencia en el proceso de tener un hijo, quedando la adopción como una opción secundaria, y que la familia extendida no tiene interferencia directa en la toma de decisión por la adopción.

Palabras clave: Parentalidad; adopción; familia; motivaciones; red familiar. 
Nas novas organizações familiares, que se apresentam na contemporaneidade, observamos uma valorização da vinculação de parentesco por aliança afetiva, como no caso da filiação por adoção. Este novo paradigma nas relações de parentesco vem sendo explicitado nas frequentes discussões sociais, representando e constituindo a aceitação social da legitimidade da filiação afetiva.

Essa aceitação diferencia-se de uma visão anterior que considerava a adoção um desvio à normalidade da filiação biológica (Schettini, Amazonas, \& Dias, 2006). Devido às mudanças da mentalidade social e ao interesse científico sobre o tema, hoje em dia, a adoção tem um lugar expressivo entre as alternativas de realização do desejo de ter um filho. Contudo, a condição da adoção ainda envolve as mais variadas representações sociais, das mais idealizadas às mais destrutivas.

Desenvolvemos um estudo ${ }^{1}$ sobre a parentalidade e a filiação adotivas, cujo objetivo geral era investigar a vivência de pais adotivos em relação à parentalidade e à filiação, no período da adolescência de seus filhos adotivos. Tínhamos como objetivos específicos investigar que questões emocionais intersubjetivas se atualizariam nesse período do ciclo familiar. Especificamente, no presente trabalho, objetivamos explorar questões referentes às motivações para a escolha da parentalidade por adoção e o lugar da rede familiar como apoio na tomada de decisão.

Organizamos a fundamentação teórica a partir de dois eixos temáticos: os processos psíquicos da parentalidade e da filiação, e aspectos envolvidos na escolha da parentalidade adotiva. A literatura usada como referência está calcada na Psicanálise e na Psicoterapia Psicanalítica de Família. As argumentações discutidas representam uma tentativa de não nos deixarmos narcotizar pela ditadura dos fatos, aparentemente óbvios e simplistas, que escamoteiam realidades psíquicas inconscientes complexas e presentes em qualquer relação humana.

\section{BASES PSÍQUICAS FUNDANTES DA PARENTALIDADE}

A família é o primeiro sistema de socialização do sujeito, constituindo a sua primeira manifestação cultural. Tal manifestação resulta de um funcionamento intersubjetivo, marcado por um percurso genealógico. É a inserção do sujeito em uma linhagem genealógica que promove o sentimento de pertença, o que viabiliza

\footnotetext{
${ }_{1}$ Pesquisa realizada com o apoio do $\mathrm{CNPq}$.
}

a capacidade de reconhecer a si mesmo e de se diferenciar.

As inscrições da história familiar são configuradas na vivência de dois processos interdependentes e simultâneos: a parentalidade e a filiação. Esses dois processos psíquicos evidenciam a construção mítica familiar, determinando o tipo de arranjo dos vínculos (Gutton, 2006). É importante enfatizar que a parentalidade não pode ser pensada sem a filiação, porque para ser pai é preciso existir o filho, a partir de uma relação dialética.

Parentalidade é entendida como uma reorganização mental que os pais vivenciam e que tem início com a realização do desejo de ter um filho. O sujeito pai/ mãe estava anteriormente na posição de filho(a), tendo uma imagem de si mesmo unicamente como filho de seu pai. Assim, a parentalidade engloba os vínculos de parentesco e os processos psíquicos que se desenvolvem a partir do desejo de ter um filho (Legendre, 2004).

A parentalidade implica na atividade de simbolização das funções materna e paterna, e diz respeito à impossibilidade de tais funções serem reduzidas ao campo biológico e social (Gutton, 2006; Bydlowski, 2010). Portanto, corresponde a um trabalho do psiquismo, como "um tipo de estrutura que se instala em ação e evolui com o desenvolvimento do indivíduo e a evolução do grupo familiar" (Solis-Ponton, 2004, p. 29).

De acordo com Lebovici (1993), o bebê faz seus pais, construindo e parentalizando-os ao mesmo tempo em que ele mesmo é constituído pelos pais. O bebê os parentaliza, por exemplo, quando reconhece a voz da mãe e do pai, seus rostos, distinguindo-os de outros semelhantes e concedendo-lhes sua atenção. Essas competências do bebê gratificam o narcisismo de seus pais, proporcionando a internalização de reconhecimento de suas funções específicas.

Autores como Levy (2009), Passos (2005), Trindade-Salavert (2010) e Zornig (2009) apontam a necessidade de o bebê ser inserido em uma cadeia geracional de filiação. Do ponto de vista de LévySoussan (2006), o trabalho psíquico próprio da filiação envolve fortemente a problemática do narcisismo parental. Ainda segundo o autor, dentre as condições para a filiação ser bem sucedida está a capacidade dos pais de fazer o filho se apropriar da história familiar de cada um dos dois e, ao mesmo tempo, permitir que ele possa construir a sua própria identidade.

\section{ADOÇÃO E SUAS VICISSITUDES}

Defendemos que a premissa básica na formação da parentalidade e da filiação adotivas é a existência de paradoxos como ruptura e vínculo, luto e investimento 
libidinal. A parentalidade e a filiação adotivas são possíveis somente quando há, necessariamente, uma descontinuidade com a família de origem da criança adotiva.

Independentemente dos motivos da descontinuidade com a família de origem, há uma separação, uma quebra no circuito geracional da criança/adolescente. A descontinuidade dos vínculos familiares de origem certamente terá efeitos diferentes, dependendo da idade da criança, das condições ambientais primitivas em que a mesma viveu e das experiências emocionais vividas nas relações objetais primitivas.

Os pais adotivos assumem um papel importantíssimo na reconstrução da identidade de seus filhos, sendo fundamental para estes a construção simbólica de sua história de vida e das descontinuidades oferecida pelos pais adotivos. A adoção, para as crianças, significa ter uma nova história, porém, ao mesmo tempo em que oferece esperança, demarca perda e separações, principalmente no caso de crianças maiores que passaram por abrigos (Peiter, 2011; Schettini Filho, 2009).

Na perspectiva dos pais adotivos, a razão manifesta para a escolha da adoção é o desejo de ter um filho. Como em toda decisão por um filho, a adoção exige tempo de reflexão e incorporação da ideia. No entanto, este é um cenário com especificidades. Os pais devem reconhecer como filho a criança gerada por outro. Além disso, eles precisam elaborar os possíveis lutos ligados à impossibilidade de gerarem um filho biológico.

Zornig (2009) faz a distinção entre o desejo de engravidar e o desejo de ter um filho. A diferença estaria na orientação do investimento libidinal, pois, no primeiro desejo, o investimento estaria direcionado para o processo de gestação e suas implicações, como, por exemplo, o sentimento de completude. Já o desejo de ter um filho envolveria o investimento entrelaçado à perpetuação geracional.

Entre os desejos imbuídos em uma adoção, podemos incluir a amplitude de questões inconscientes envolvidas na vontade de ter filhos, de ser pai e na atitude de adotar. De fato, o que está sendo apontado é que, em relação às profundezas do inconsciente que alicerçam a demanda por um filho, não existe certeza, e para cada sujeito isso se configura de modo bem singular.

$\mathrm{Na}$ literatura, encontramos a ênfase na ideia de refletir sobre as motivações dos pais para adotar um filho, tendo como função a compreensão mais apurada sobre o desenvolvimento dos vínculos (Cardoso \& Baiocchi, 2014; Ladvocat, 2014, 2010; Levinzon, 2000; Schettini Filho, 2008; Trindade-Salavert, 2010). As motivações são classificadas por sua finalidade e fonte de origem, como a infertilidade, a perda de um filho, a transmissão familiar e a filantropia, entre outras. Algumas delas são apontadas como motivações que podem trazer consequências dramáticas para a adoção. No entanto, Weber (2001) constatou, em suas pesquisas com famílias adotivas, que não existe correlação entre a motivação dos adotantes e o sucesso da adoção.

Schettini Filho (2008) enfatiza que, dependendo do tipo de motivação para se optar pela adoção, a saúde familiar poderá ser comprometida, principalmente em situações nas quais a decisão emerge de uma demanda secundária e circunstancial. O que seria isso? O desejo de ter um filho adotivo fica em um nível secundário, pois o desejo primário seria, por exemplo, a substituição de um filho morto, a negação da ferida narcísica provocada pela infertilidade, ou a consolidação da imagem de bondade (filantropia), entre outras. Segundo o referido autor, as principais origens motivacionais podem ser localizadas em três campos: o biológico (representado pela infertilidade), o social (representado pelos valores humanitários) e o emocional (representado por um filho morto ou por transmissão familiar).

A infertilidade de um dos cônjuges é apontada como a razão mais comum para a decisão da adoção. Nestes casos, essa decisão resultaria em uma solução para a falha biológica, sendo uma alternativa que facilita o caminho de reparação desta falha e de concretização do desejo de ter um filho (Levinzon, 2014). Schettini, Amazonas e Dias (2006), bem como Lopes (2008) ressaltam que a impossibilidade biológica de gerar um filho deve ser seguida de um luto e um processo de aceitação da perda do "filho biológico". Há um consenso entre os estudiosos de que, nessas situações, o desejo de adoção deve ser efetivamente trabalhado, a fim de permitir ao casal uma elaboração da ferida narcísica e uma compreensão da dinâmica psíquica conjugal. Logo, a decisão de adotar pode ter origem nas mais variadas motivações, conscientes e inconscientes, as quais estão correlacionadas à história, às fantasias infantis de cada membro do casal adotivo e à dinâmica conjugal.

A condição da parentalidade e da filiação adotivas é um desafio, na medida em que a família será constantemente colocada à prova na sua capacidade de suportar o que está "solto", separado, dissociado, achando-se de um lado os laços biológicos e, de outro, os laços jurídicos e psíquicos (Lévy-Soussan, 2006). Diante disso, a lei terá um valor continente nessa "soltura", pois permitirá a sustentação da descontinuidade do fator biológico com a fundação da filiação afetiva pelo discurso jurídico. No contexto da adoção, a filiação biológica está dissociada da filiação afetiva. 
A ausência do fator biológico exigirá uma valorização do papel jurídico e dos aspectos afetivos para a legitimação dos laços de parentesco. Tal importância da lei ocorre porque o jurídico reconhece socialmente a interrupção da filiação biológica e dá lugar à filiação adotiva (Lévy-Soussan, 2006). No plano psíquico, a garantia do laço jurídico para a validade da filiação adotiva permite que pais e filhos experimentem, até certo ponto, seus sentimentos hostis (Machado \& Féres-Carneiro, 2012).

Schettini Filho (2009) reforça que à família adotiva resta vivenciar intensamente a sua condição de vinculação afetiva e toda a sua história de adoção, sem se sentir agredida por sua diferenciação. Contudo, sabemos que, no mundo inconsciente, as leis da lógica fogem às da razão, abrigando fantasias desconhecidas, cuja incidência pode ser tóxica à saúde do vínculo paterno-filial.

Autores como Souza e Casanova (2011) destacam a família extensa como uma rede de apoio, muito significativa, na preparação da chegada da criança, legitimando o lugar da mesma na cadeia geracional e recriando mutuamente os papéis e as funções familiares. Marinopoulos, Sellenet e Vallée (2003) destacam que, inegavelmente, a família como um todo participa do processo de integrar a criança à cadeia genealógica. Os laços de parentesco na adoção são unicamente simbólicos, por isso o grupo familiar se insere como um fator continente ao sustento da filiação imaginário-afetiva (Rotenberg, 2011). Segundo Schettini Filho (2009), são os avós que introduzem o neto na genealogia da família, validando a ascendência do filho adotivo.

\section{REDE SOCIAL DE APOIO}

A rede social de apoio é composta pelas interações que vinculam as pessoas mutuamente. Gonçalves, Pawlowski, Bandeira e Piccinini (2011) constataram, a partir de uma revisão de estudos brasileiros, que existem várias terminologias para se referiar à noção de rede de apoio social, porém sem variação quanto a sua definição. Sluzki (2006) ressalta que uma rede social de apoio é significativa para o equilíbrio do sistema, não se restringindo à família nuclear ou extensa. Todo conjunto de vínculos interpessoais do sujeito é fundamental para a manutenção da vida dos mesmos, tais como a família extensa, amigos, relações de trabalho e de estudo, inserção comunitária e práticas sociais.

Observamos uma ampliação na literatura dedicada ao entendimento da relevância da rede social de apoio nas mais variadas questões familiares (Araújo \& Aiello,
2013; Macedo, 2013; Martins, 2011). Dessen e Braz (2000) argumentam que esses estudos são fundamentais, posto que vários sistemas externos à família nuclear exercem influências no desenvolvimento dos membros familiares e em sua dinâmica de funcionamento interno.

A compreensão desses vínculos interpessoais nos possibilita avaliar a promoção do bem-estar ou mal-estar do sistema, a perturbação, ou não, em processos de adaptação, principalmente, nas famílias ditas contemporâneas, cujos padrões muitas vezes apresentam-se difusos e com laços esgarçados. Como consequência dessa característica, torna-se cada vez mais complexo definir os contornos que delimitam as famílias, formando com a rede social arranjos que viabilizam a própria condição de existência da família (Sarti, 2010).

Um aspecto contemporâneo da rede social de apoio é que muitas vezes ela passa a ser vivenciada como um vínculo de parentesco fundamental, principalmente, em famílias de seguimentos sociais desfavorecidos e/ou vulneráveis, devido à intensa participação, influência e dependência da família na manutenção de seu funcionamento. Sarti (2010) aprofunda esta ideia formulando que há um papel de referência simbólica das redes sociais de apoio, que organiza e ordena a percepção de mundo daqueles que recebem seu suporte.

\section{MÉTODO}

A partir dos fundamentos teóricos aqui apresentados, este estudo tem como objetivo explorar questões referentes às motivações para a escolha da parentalidade por adoção e o lugar da rede social como apoio na tomada de decisão dos pais adotivos. Cabe destacar que quando utilizamos o termo "pais" estamos fazendo referência tanto a pais quanto a mães.

Utilizamos uma metodologia de pesquisa qualitativa. Para atingirmos o objetivo delineado, foram realizadas 10 entrevistas semiestruturadas com sujeitos independentes. Os filhos adotivos desses sujeitos se encontravam no período da adolescência, entre os 13 e 18 anos, conforme postula Emmanuelli (2005). Com relação à configuração familiar, apenas duas mães formavam famílias monoparentais heterossexuais, quando adotaram seus filhos. Ambas tiveram um filho biológico no casamento e após a separação desejaram adotar um filho. Os demais participantes pertenciam a famílias heterossexuais com as seguintes configurações: três deles permaneciam casados, dois tinham união estável, três eram separados e um era viúvo. Como critério de delimitação e de aproximação 
do perfil dos sujeitos, foram entrevistados pais, das classes média e alta da população Estado do Rio de Janeiro, que adotaram os filhos até os 12 anos de idade, cuja adoção não fosse um segredo na família. Para a análise do material obtido por meio das entrevistas foi utilizado o método análise de conteúdo (Bardin, 2010).

Em todos os casos descritos, os nomes foram substituídos, assim como alguns detalhes biográficos e da história familiar. Foi necessário fazer determinadas alterações para que as identidades das famílias fossem preservadas e, assim, se mantivesse o compromisso ético do sigilo garantido aos entrevistados. Na Tabela 1 , encontram-se mais detalhadamente os dados biográficos de cada um dos sujeitos.

\section{RESULTADOS E DISCUSSÃO}

\section{Motivações para adoção}

Os discursos dos entrevistados levaram a constatar a grande variedade de motivações, conscientes e inconscientes, envolvidas na escolha da parentalidade por adoção. O primeiro ponto observado foi que para seis dos entrevistados que vivenciaram algum problema de fertilização, seja por parte deles ou dos cônjuges, a adoção veio como uma opção secundária de ter um filho. Esse resultado corrobora a literatura (Schettini Filho, 2008; Lopes, 2008; Schettini, Amazonas \& Dias, 2006), quanto à constituição de uma marca nos futuros pais, pois a condição de ser pai e mãe se inicia com a frustração em sua condição de reproduzir, portanto, se defrontam com uma perda e a necessidade de elaborar um luto.
Percebemos, por meio das narrativas, que a maioria dos entrevistados não mencionou de forma explícita a frustração e o sofrimento de não poder ter o filho biológico. Apenas a Mãe 6 fez referência à sua tristeza, o que nos levou a pensar que, possivelmente, seja um luto de difícil elaboração, sendo necessário recorrer a defesas mais rígidas.

"Eu tentei engravidar, fiz inseminação e não consegui. Tentei engravidar e não consegui. E um belo dia, quando uma das fertilizações que eu fiz, que não deu certo, eu fiquei muiiito triste! E eu dizia: 'Também, adotar eu não adoto', eu falava. E eu viajei com meu marido, até para dar uma relaxada, porque eu tava bem triste". (Mãe 6)

"Eu sempre pensei assim: que filho adotado, ou biológico, não tem diferença nenhuma, tá? De repente entra a religiosidade nisso. (...) Começamos a tentar, e eu não conseguia. Ai, descobrimos que eu tinha as trompas todas obstruidas. Nós fomos procurar um médico para fazer a inseminação. Isso há 20 anos atrás. (...) Cheguei a tomar algumas medicações. Mas, depois resolvemos apelar para adoção". (Mãe 3)

No discurso da Mãe 3, podemos observar que a afirmação que ela faz, sobre não haver diferenças entre a parentalidade biológica e a parentalidade adotiva, é constituída de representações contraditórias. Consideramos que, se realmente ela considerasse iguais as duas formas de parentalidade, teria pensado na

TABELA 1

Dados biográficos dos sujeitos

\begin{tabular}{|c|c|c|c|c|c|}
\hline & Idade & Estado civil & Filho adotivo & Época da adoção & Filho biológico \\
\hline Pai 1 & 63 & Separado & Filho - 18 anos & Bebê de 1 ano & - \\
\hline Pai 2 & 61 & Viúvo & Filha - 17 anos & Bebê de 1 mês & $\begin{array}{l}\text { Filha }-30 \text { anos } \\
\text { Filho }-27 \text { anos }\end{array}$ \\
\hline Mãe 1 & 58 & Casada & Filho - 17 anos & Bebê de 4 meses & 3 Filhas entre 36 e 27 anos \\
\hline Mãe 2 & 33 & União estável & Filha -14 anos & Pré-adolescente 12 anos & - \\
\hline Mãe 3 & 51 & Casada & Filho - 18 anos & Bebê 1 mês & - \\
\hline Mãe 4 & 50 & Separada & Filho - 14 anos & Criança 7 anos & Filho -18 anos \\
\hline Mãe 5 & 65 & União estável & Filho - 17 anos & Bebê entre o $1^{\circ}$ e $3^{\circ}$ mês & - \\
\hline Mãe 6 & 45 & Casada & $\begin{array}{l}\text { 1 } \text { Filha }-15 \text { anos } \\
\text { 2o Filho }-19 \text { anos } \\
\text { 3o Filho }-17 \text { anos } \\
\text { 4o Filho }-11 \text { anos }\end{array}$ & 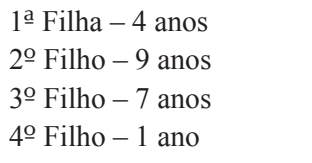 & - \\
\hline Mãe 7 & 46 & Separada & Filho - 13 anos & 9 meses & Filha -25 anos \\
\hline Mãe 8 & 55 & Separada & Filho - 15 anos & Bebê "com dias de vida" & - \\
\hline
\end{tabular}


inseminação e na adoção simultaneamente. Percebemos claramente que, para alguns dos entrevistados, existe uma hierarquia nas alternativas de parentalidade, a qual é definida pelos significados inconscientes direcionados a cada uma dessas alternativas.

A Mãe 6, por exemplo, explicita que de início não queria pensar em adoção. Esta mãe mostra-se em contato com sua realidade emocional. Talvez isso tenha contribuído para ela ser capaz de superar a sua rejeição à alternativa da adoção. Acreditamos que quanto mais o sujeito puder entrar em contato com suas experiências emocionais, mais ele não precisará recorrer a defesas rígidas, como a recusa da sua realidade emocional, e mais terá condições psíquicas de entrar em contato com a realidade emocional do outro, no caso, de seu filho adotivo.

A partir da análise das entrevistas, percebemos que as razões motivacionais formam uma história mítica que dá um sentido consciente ao desejo da parentalidade por adoção.

"Na verdade, a experiência é a seguinte: nós não tínhamos mais a intenção de adotar filhos. A gente sempre pensou em um dia, em algum momento, adotar uma criança. (...) Quando a gente comentava assim: 'não foi possível aquele projeto, né, de adotar uma criança', o meu marido dizia: 'Nós vamos adotar uma menina, isso se nós fôssemos escolher'. Porque ele não queria que tivesse aquela sensação de que: 'olha, nós só adotamos porque era um menino'. E no final veio um menino, sem que a gente procurasse". (Mãe 1)

"Bem, eu posso ter filhos, mas qualquer gravidez que eu tenha é uma gravidez de risco. Eu não tinha esse tipo de sonho. Eu não conseguia, não me via em uma situação (de gravidez) ... parar minha vida, né. (...) Mas eu sempre tive vontade de ter mais alguém na família, de desenvolver mais assiduamente esta questão da maternidade. (...) Eu fui criada basicamente pela minha mãe. O meu padrasto faleceu, eu era adolescente. Minha mãe que me criou. E ela casou a segunda vez, quando eu tinha cinco anos de idade. Aos 13 anos, meu padrasto faleceu. E, assim... eu sempre aprendi o seguinte: 'Eu tenho que ser independente, eu tenho que correr atrás da minha vida'. Entendeu?" (Mãe 2)

A história mítica parece permitir a expressão de questões inconscientes envolvidas na formação da escolha pela adoção, como ilustram as falas acima. Observamos que algumas motivações eram naturalmente apontadas como a única razão da escolha pela adoção, enquanto outros aspectos igualmente envolvidos na formação da escolha eram mencionados indiretamente. Esta constatação vai ao encontro do entendimento de que a parentalidade é um trabalho psíquico que se instala a partir do processo de desenvolvimento do indivíduo, da evolução do grupo familiar, e do conjunto de desejos infantis (Bydlowski, 2010; Gutton, 2006; Solis-Ponton, 2004).

"A adoção sempre esteve assim, desde os 15 anos, no ar, né?! E quando eu me casei com meu exmarido, ele falou: 'Olha, se a gente não tiver, a gente adota'. Isso já foi o máximo! E eu fiz alguns tratamentos, mas os tratamentos que eu fiz me engordaram muito, eu tive uma reação hormonal e chegamos à conclusão de que não valia a pena... E foi ai que a gente partiu para a adoção. (...) Meu pai começou a ficar doente quando eu tinha 18 anos. Ele morreu quando eu tinha 21. Então, isso abalou um pouco, e uma coisa que me chama atenção agora: quando eu tinha 15 anos, eu sempre pedi à minha mãe, apesar dos cinco filhos, eu sempre pedi que ela adotasse uma criança. (...) É porque eu queria um bebezinho para cuidar e que não sei o que..." (Mãe 8)

No que concerne as motivações para a adoção, constatamos que são amplas as motivações inconscientes envolvidas em uma adoção, tais como: a transmissão psíquica familiar do marido e o desejo da Mãe 1 de ter um filho homem; o desamparo vivido pela Mãe 2, que sofreu com a ausência do pai e possivelmente teve que ser mãe dela mesma para não sobrecarregar sua mãe; e por fim, o desejo de um novo membro familiar após a perda do pai Mãe 8. Esta percepção alinha-se às postulações de Cardoso e Baiocchi (2014), Ladvocat (2014; 2010), Levinzon (2000), Schettini Filho (2008) e Trindade-Salavert (2010) que ressaltam a variedade das origens motivacionais e o quanto é importante identificá-las para a compreensão do desenvolvimento dos vínculos.

No entanto, devemos ter em mente o limite dessa compreensão, pois existem representações inconscientes associadas ao desejo de adotar e ao significado de ser pai/mãe e de ter um filho, às quais talvez nunca tenhamos acesso. Os trechos destacados acima ilustram, também, a complexidade da realização do desejo de ter um filho e da alternativa da adoção. Tal constatação realça a formulação de Weber (2001) sobre a impossibilidade de relacionar diretamente a motivação dos adotantes ao sucesso da adoção. 
Percebemos, a partir das narrativas, que até mesmo as preferências de cada pai e mãe, como o sexo da criança ou a idade, encontram motivações em sua própria história. A Mãe 7 aborda esta questão:

"A gente, óbvio, que tem que trabalhar os conceitos, tem que trabalhar as coisas, mas você não pode, e isso eu debato muito, você não pode fazer uma pessoa adotar uma criança negra se ela não tem preparo para aquilo. Eu defendo a escolha do perfil! Você não pode imputar uma pessoa a adotar uma criança mais velha... eu não tenho condições de adotar uma criança mais velha, eu não teria condições de fazer uma adoção tardia".

O relato acima leva a uma reflexão sobre a escolha do perfil ser muito mais do que cognitiva ou preconceituosa. No caso da Mãe 2, por exemplo, ela comentou que sua mãe assumiu as funções de mãe e de pai, devido às mortes precoces do primeiro e do segundo marido. Talvez por alguma razão muito primitiva, ela não se via grávida, não queria ter um bebê, havendo desejo de ter um filho, porém não de engravidar. Esse dado corrobora as formulações de Zornig (2009) sobre distinção entre o desejo de engravidar e o desejo de ter um filho. Para essa mulher, a gestação não é condição de maternidade, e esta independe daquela, sendo a gestação inviável psiquicamente de ser vivida.

Percebemos em algumas das falas dos pais que o perfil do filho, definido pelos candidatos à adoção, tem origem nas vivências emocionais ao longo das suas próprias histórias. Esse dado corrobora a afirmação de Lévy-Soussan (2006) de que o trabalho psíquico próprio da filiação envolve fortemente a problemática do narcisismo parental e a capacidade dos pais de se apropriar da própria história familiar. As falas abaixo da Mãe 5 também ilustram essa questão.

"Mas, a psicóloga vinha na minha casa e a assistente social vinha também. Aí, ela dizia para mim: 'Você tem certeza que você vai querer um bebê?' Eu falei: 'Eu quero um bebê porque eu quero ser mãe. Quero sentir as coisas convincentes, embora não vá engravidar'. Ela dizia: 'Será que não era melhor uma criança maior?' Eu falei: 'Eu não quero criança maior. Eu quero pequenininho'. Ai aquilo foi passando e eu fiquei dois anos na fila, entendeu? (...) Ah, e outra coisa que eu queria também! Eu queria que fosse homem, eu não sei por quê. Porque o homem sofre menos, não sei”. (Mãe 5)
"Meu pai brigava muito com a minha mãe também. Eu gostava muito do meu pai, mas eu detestava aquela atitude dele, entendeu, com a minha mãe. Agora, eu gostava muito da minha mãe também. Mas a minha mãe teve dois (ato falho), três filhos. A minha mãe não era muito apaixonada por mim. Ela gostava mais dos filhos homens, que ela tinha dois". (Mãe 5)

Para a Mãe 5, ser mãe requer um bebê. Por isso refutou a sugestão dos profissionais de realizar uma adoção tardia, sugestão motivada pelos seus 45 anos de idade à época. Ela também preferiu que seu bebê fosse um menino, pois tinha a crença de que homem sofreria menos. Em sua história de vida, declara que a mãe tinha preferência por filhos homens e que não se sentia amada por ela, talvez nem mesmo reconhecida. Além disso, revelou que o pai era agressivo com sua mãe, talvez constituindo a representação da condição de mulher como um ser vulnerável, sofredor e pouco amorável.

Por mais que uma família faça tudo de melhor por seus filhos, isso não será garantia de que eles alcancem a plena maturidade. O desenvolvimento e o sucesso das relações dependem de muitos fatores, como a interação familiar, as histórias de vida e a economia interna de cada indivíduo. Todos esses fatores devem ser levados em consideração para que sejam entendidas determinadas escolhas e formações de vínculos familiares.

\section{Rede de apoio}

Os dez pais entrevistados foram unânimes ao manifestarem que o posicionamento familiar não influenciou na escolha da parentalidade por adoção. Para os sete entrevistados que eram casados à época da decisão, a escolha da adoção foi determinada, segundo eles, por um consenso entre os membros do casal. Parece haver, portanto, uma diferenciação feita pelos pais entre a tomada de decisão e a legitimação do lugar da criança na família. Notamos isso, com muita clareza, nos trechos abaixo.

"Falavam que eu não deveria arrumar sarna pra me coçar.. Mas depois, hoje ela é superaceita na família, ninguém percebe, eu não percebo nenhuma discriminação assim. Muito pelo contrário. Mas era muito tabu". (Pai 2)

Para outros entrevistados, aparentemente, o fator crucial para adoção foi o próprio desejo, e no nível manifesto não atribuíram às opiniões da família e dos amigos um caráter decisivo. Porém, no momento 
em que a criança era incluída na família, o papel da família extensa e de outros grupos sociais parecia ser relevante para os entrevistados. Este dado corrobora com Souza e Casanova (2011) sobre a família extensa ser significativa na inclusão da criança na cadeia genealógica.

Em vários momentos, a decisão parece estar pautada em uma independência, porém se pensarmos, especialmente no que diz respeito às questões inconscientes, essa demonstração de autonomia muitas vezes encontra-se motivada por processos ligados à relação com a família extensa. Talvez as famílias neguem a relevância das opiniões sociais como uma tentativa reativa de não se sentirem tão influenciadas e dependentes de opiniões externas. Observamos que maneira como o grupo familiar lidou e se vinculou ao recém-chegado foi levada em consideração por esses pais. Isso corrobora a afirmação de Marinopoulos et al. (2003) de que, inegavelmente, a família como um todo participa do processo de integrar a criança à cadeia genealógica. Ou seja, embasados nos dados que obtivemos, a família extensa é indispensável para a integração da criança à família, mas não relevante na decisão da escolha. A sequência da fala da Mãe 7 serve como ilustração de nossas colocações.

"Eu adotei porque eu quis adotar outro filho. Entendeu? A maneira como a pessoa coloca este filho na sociedade é a maneira como a sociedade vai responder. (...) Então assim, a minha família aceitou muito bem. Tirando a minha mãe". (Mãe 7)

Recorrendo à ideia de Lebovici (1993) sobre o bebê parentalizar os pais, pensamos que a aceitação da rede familiar será, também, influenciada pela maneira como a criança se vinculará à família, sendo a constituição do parentesco afetivo um ato de reciprocidade. Como fora bem ilustrado nos trechos do Pai 2 e da Mãe 7, a família extensa não aceitava no primeiro momento, mas foi modificando a postura a partir da convivência. Ressaltamos, portanto, que a criança tem um papel aditivo na conquista de sua integração familiar, havendo um fator de reconhecimento mútuo para a consolidação dos laços de parentesco. Porém, devemos destacar que ter um papel aditivo não significa que ela seja a responsável pelo tipo de vinculação, até mesmo porque, como criança, ela apresenta muito menos recursos psíquicos para assumir esse lugar.

Como foi apresentado no quadro biográfico, quatro dos entrevistados já tinham filhos biológicos antes da adoção, destacando-se o caso da Mãe 6, que já tinha uma filha adotiva quando adotou três irmãos. No discurso dos sujeitos, observamos uma semelhança, que foi a participação dos filhos na chegada do adotivo, seja na escolha do nome, na arrumação do quarto, no desejo de adotar aquela criança específica.

(Sobre a reação da filha à notícia da adoção de outros filhos.)

"Ela que escolhia tudo para o quarto deles. Então, ela se sentia a responsável. Me lembro que a gente tava... (...) Nós saímos juntas, escolhemos os lençóis, escolhemos isso, aquilo outro". (Mãe 6)

Dessa forma, os pais incluíram seus filhos no projeto da adoção, dando importância à participação deles, permitindo a germinação da vinculação fraterna no psiquismo do filho. Intuitivamente os pais tomam uma atitude que transforma a decisão da adoção, que não compartilha o legado genético, em um elemento comum aos filhos viabilizando a criação de uma aliança fraterna, corroborando com as pontuações de Ducatti (2004). Na medida em que os laços de parentesco na adoção são unicamente simbólicos, ressaltamos o quanto o grupo familiar extenso e o grupo social se inserem como fatores continentes, e formando uma rede de apoio significativa para o sustento da filiação imaginário-afetiva, organizando e constituindo simbolicamente a percepção dos laços de parentesco, indo ao encontro de seu papel contemporâneo para as novas configurações familiares (Sarti, 2010).

\section{CONSIDERAÇÕES FINAIS}

A experiência de parentesco é tecida pelo intercâmbio de conteúdos psíquicos conscientes e inconscientes de todos os membros do grupo. Procuramos, em nossa análise, articular de forma criteriosa os dados e a teoria, buscando uma compreensão, principalmente, no que se refere à dinâmica inconsciente.

Observamos que a semente da potencialidade para a constituição de vínculo afetivo adotivo aparece muito antes do encontro entre pais e filhos. Ela tem sua origem na história familiar e de vida dos pais adotivos, como ilustram as narrativas de pais que já pensavam em adotar um filho, mesmo sem uma condição ou uma razão aparente.

Verificamos que poucos pais, os que lidaram com a infertilidade, mencionaram de forma explícita a frustração e o sofrimento de não poder ter o filho biológico, e pensamos que esse silêncio possa evidenciar uma atitude defensiva pela dificuldade de elaboração do luto pela perda do filho biológico. Contudo, não acreditamos que seja a infertilidade ou outras razões em si que possam fazer os laços de parentesco adotivos se tornarem vulneráveis. 
Vimos que o que fragiliza os laços são as fantasias e os mecanismos de defesa que operam na tentativa do sujeito de não entrar em contato com a dor presente na constituição do desejo de adoção. E a recusa defensiva de lidar com a dor ameaça a solidificação do sentimento de pertencimento e do reconhecimento do seu próprio lugar na vida de cada membro familiar.

Constatamos, também, que apesar de os pais verbalizarem não fazer distinção entre a parentalidade biológica e a parentalidade adotiva, existe uma atitude contraditória, já que a maioria explicitou uma hierarquia de preferência no processo de ter um filho, ficando a adoção como uma escolha secundária. A nosso ver, se realmente alguns pais considerassem iguais as duas formas de parentalidade, teriam pensado na inseminação e na adoção simultaneamente.

Verificamos que a tomada de decisão pela adoção, aparentemente, não sofreu interferência direta da família extensa, ficando centrada apenas no casal ou/e nos filhos. A função da família extensa apareceu como fundamental na inserção da criança adotada na cadeia geracional após a adoção. Evidenciou-se a função ativa da criança adotada em sua introdução na genealogia da família, tendo ela uma significativa participação na validação do parentesco adotivo, a partir da viabilização de um laço amoroso com os demais membros da família.

Pelo que pudemos constatar, a definição do perfil dos filhos desejados tem sua origem de significados na história de cada um deles. O perfil representa a busca de um semelhante, uma familiaridade definida pela identificação, que será fundamental para a inserção da criança na identidade parental e para a construção do senso de pertencimento. Entendemos que as definições de sexo, de idade e demais características representam aspectos ligados à trama inconsciente, sendo psiquicamente importante para os pais poder transmitir o legado familiar e se vincular à criança. Pensamos que a escuta oferecida a essas famílias deve ser sensível no que diz respeito ao jogo de representações inconscientes que estruturam a parentalidade e a filiação adotivas.

\section{REFERÊNCIAS}

Araújo, G. M. S. \& Aiello, A. L. R. (2013). Rede social de apoio de mães com deficiência intelectual. Psicologia: Reflexão e Crítica, 26(4), 752-761. http://dx.doi.org/10.1590/s0102-79722013000400016

Bardin, L. (2010). L'analyse de contenu. Paris: PUF.

Bydlowski, M. (2010). Je rêve um enfant: l'expérience intérieure de la maternité. Paris: Odile Jacob.

Cardoso, V. L. \& Baiocchi, A. (2014). Preparação para adoção - o começo de uma nova família. In C. Lavocat \& S. Diuana (Eds.), Guia de adoção - No jurídico, no social, no psicológico e na família (pp. 53-64). São Paulo: Roca.

Dessen, M. A. \& Braz, M. P. (2000). Rede social de apoio durante transições familiares decorrentes do nascimento de filhos. Psicologia: Teoria e Pesquisa, 16(3), 221-231. http://dx.doi.org/10.1590/s0102-37722000000300005

Emmanuelli, M. (2005). Que sais-je? - L'adolescence. Paris: Puf.

Gonçalves, T. R., Pawlowski, J., Bandeira, D. R., \& Piccinini, C. A. (2011). Avaliação de apoio social em estudos brasileiros: aspectos conceituais e instrumentos. Ciência \& Saúde Coletiva, 16, 1755-1769. http://dx.doi.org/10.1590/ S1413-81232011000300012

Gutton, P. (2006). Parentalité. Revue Adolescence, 24(1), 9-32. http://dx.doi.org/10.3917/ado.055.0009

Ladvocat, C. (2010). A terapia da família adotiva. Revista Brasileira de Terapia família. ABRATEF, 2(1), 96-104.

Ladvocat, C. (2014). Campo clínico da prevenção na adoção. In C. Lavocat \& S. Diuana (Eds), Guia de adoção - No jurídico, no social, no psicológico e na família (pp.149-157). São Paulo: Roca.

Lebovici, S. (1993). On intergenerational transmission: filiation from afiliation. Infant Mental Health Journal, 14(4), 260-272.http://dx.doi.org/10.1002/1097-0355(199324)14:4<260::AID-IMHJ2280140402>3.0.CO;2-Z

Legendre, P. (2004). Filiation - Fondement généalogique de la psychanalyse para Alexandra Papageorgiou-Legendre. Paris: Fayard, Leçon IV, 235 p.

Levinzon, G. K. (2014). Parentalidade adotiva - os pais suficientemente bons. In C. Lavocat \& S. Diuana (Eds.), Guia de adoção - No jurídico, no social, no psicológico e na família (pp. 307-312). São Paulo: Roca.

Levy, L. (2009). Adoção internacional: filiação e processo de luto. In T. Féres-Carneiro (Ed.), Casal e família: permanências e rupturas (pp. 59-70). São Paulo: Casa do Psicólogo.

Lévy- Soussan, P. (2006). La filiation à l'épreuve de l'adolescence. Revue Adolescence, 24(1), 101-110. http://dx.doi. org/10.3917/ado.055.0101

Lopes, H. P. (2008). Gerar/ter um filho: o processo de reprodução assistida como inclusão de terceiros. In R. M. Macedo (Ed.), Terapia familiar no Brasil na última década (pp. 212-220). São Paulo: Roca. 
Macedo, T. E. P. M., Fernandes, C. A., \& Costa, I. S. (2013). Rede de apoio social de pacientes com diagnóstico de esquizofrenia: estudo exploratório. Estudos de Psicologia (Natal), 18(4), 639-647. http://dx.doi.org/10.1590/S1413294X2013000400012

Martins, E. (2011). Família em situação de risco e rede social de apoio: um estudo em comunidade de periferia metropolitana.Revista@mbienteeducação,4(10),60-71.

Machado, R. N. \& Féres-Carneiro, T. (2012). A parentalidade adotiva em questão. Trieb - Sociedade Brasileira de Psicanálise do Rio de Janeiro (Rio de Janeiro), XI(1-2), 103-122.

Marinopoulos, S., Sellenet, C., \& Vallée, F. (2003). Moïse, oedipe, superman... de l'abandon à l'adoption. Paris: Fayard. $352 \mathrm{p}$.

Passos, M. C. (2005). Nem tudo que muda, muda tudo: um estudo sobre as funções da família. In T. Féres-Carneiro (Ed.), Familia e casal: efeitos da contemporaneidade (pp. 11-23). Rio de Janeiro: Editora PUC-Rio.

Peiter, C. (2011). Adoção: vínculos e rupturas: do abrigo à família adotiva. São Paulo: Zagodoni Editora.

Rotenberg, E. (2011). Adopción: Construyendo nuestra família. Buenos Aires: Lugar Editorial.

Sarti, C. (2010). Famílias enredadas. In A. R. Acosta, \& M. F. Vitale (Ed.), Família: redes, laços e políticas públicas (pp. 21-44). São Paulo: Cortez - Coordenadoria de Estudos e Desenvolvimento de Projetos Especiais.

Schettini Filho, L. (2008). Compreendendo os pais adotivos. 2aㅡ. ed. Recife: Bagaço.

Schettini Filho, L. S. (2009). Pedagogia da adoção: criando e educando filhos. Petrópolis: Vozes.

Schettini, S. S. M., Amazonas, M. C. L. A., \& Dias, C. M. S. B. (2006). Famílias adotivas: identidade e diferença. Psicologia em Estudo, 11(2). http://dx.doi.org/10.1590/S1413-73722006000200007

Solis-Ponton, L. (2004). A construção da parentalidade. In L. Solis-Ponton (Ed.), Ser pai, ser mãe - Parentalidade: Um desafio para o terceiro milênio. São Paulo: Casa do Psicólogo.

Souza, H. P. \& Casanova, R. P. S. (2011). Adoção: o amor faz o mundo girar mais rápido. Curitiba: Juruá.

Sluzki, C. (2006). A rede social na prática sistêmica. São Paulo: Casa do Psicólogo.

Trindade-Salavert, I. (Org.). (2010). Os novos desafios da adoção: Interações psíquicas, familiares e sociais. Rio de Janeiro: Companhia de Freud.

Weber, L. N. D. (2001). Aspectos psicológicos da adoção. Curitiba: Juruá.

Zornig, S. (2009). Transmissão psíquica uma via de mão dupla? In T. Féres-Carneiro (Ed.), Casal e família: permanências e rupturas (pp.25-39). São Paulo: Casa do Psicólogo.

\footnotetext{
Autores:

REBeCA NonAto MACHADO - Doutora, Pontifícia Universidade Católica do Rio de Janeiro

TEREZINHA FÉRES-CARNEIRO - Doutora, Pontifícia Universidade Católica do Rio de Janeiro

Andrea SeiXas Magalhães - Doutora, Pontifícia Universidade Católica do Rio de Janeiro
}

Endereço para correspondência:

Rua Xavier da Silveira, 50, apt. 404 - Copacabana

CEP 22061-010 Rio de Janeiro, RJ, Brasil

Aceito em: 04.02.15

Recebido em: 10.07 .15 